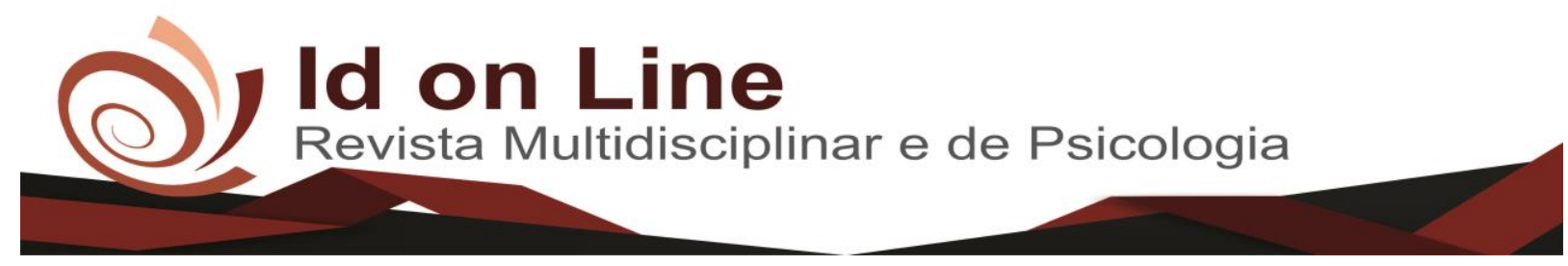

Artigo de Revisão

\title{
Liderança do Enfermeiro: Reflexões Sobre o Papel do Enfermeiro no Contexto Hospitalar
}

\author{
Aline Bezerra Sobrinho ${ }^{1}$; Juliana Maria Silva Bernardo²; Ana Carla Silva Alexandre ${ }^{3}$; \\ Cláudia Daniele Barros Leite-Salgueiro ${ }^{4}$; Valdeilson Lima de Oliveira ${ }^{5}$
}

\begin{abstract}
Resumo: A Liderança tem se constituído, uma preocupação recente com foco de atenção dos enfermeiros e administradores dos serviços de saúde, pois estes profissionais representam, em termos quantitativos, parcela significativa dos recursos humanos alocados nas instituições, especialmente nos hospitais, e, portanto, interfere diretamente na eficácia, na qualidade e no custo da assistência à saúde prestada. Objetivo: caracterizar a produção cientifica, a respeitos de publicações referentes a liderança na enfermagem em unidades hospitalares. Método: consiste numa revisão integrativa que reúne de forma sistemática e ordenada os resultados oriundos de pesquisas sobre liderança. A amostra final foi composta por 27 artigos. Resultados e Discussão: Observa-se que 59,25\% dos artigos, foram publicados em periódicos Qualis Capes A para Enfermagem, e 70,37\% possuem enfermeiros como principal público alvo. Verifica-se ainda o nível IV de evidência e predominância de estudos descritivos com $62,96 \%$ com delineamento não experimental como pesquisa descritiva correlacional e qualitativa ou estudos de caso. A liderança na enfermagem é fundamental para o empoderamento e reconhecimento da categoria profissional. Conclusão: Observa-se a necessidade de publicações com maior nível de evidencia científica para assim consolidar o impacto do exercício da liderança como ferramenta de qualidade na assistência de Enfermagem no âmbito hospitalar.
\end{abstract}

Palavras-chave: Liderança. Enfermeiros. Unidade Hospitalar.

\section{Nurse Leadership: Reflections on the Role of the Nurse in a Hospital Context}

\begin{abstract}
Leadership has become a recent concern with attention of nurses and administrators of health services, since these professionals represent, in quantitative terms, a significant part of the human resources allocated in institutions, especially in hospitals, and, therefore, directly affects the effectiveness, quality and cost of health care provided. Objective: to characterize the scientific production, with respect to publications referring to nursing leadership in hospital units. Method: it consists of an integrative review that gathers in a systematic and orderly way the results from research on leadership. The final sample consisted of 27 articles. Results and Discussion: It is observed that $59.25 \%$ of the articles were published in Qualis Capes A journals for Nursing, and $70.37 \%$ have nurses as the main target audience. Level IV of evidence and predominance of descriptive studies with $62.96 \%$ with non-experimental design as descriptive correlational and qualitative research or case studies are also verified. The leadership in nursing is fundamental for the empowerment and recognition of the professional category. Conclusion: It is observed the need for publications with a higher level of scientific evidence to consolidate the impact of the exercise of leadership as a quality tool in nursing care in the hospital.
\end{abstract}

Keywords: Leadership. Nurses. Hospital Unit.

\footnotetext{
${ }^{1}$ Autora. Discente do Curso de Bacharelado em Enfermagem do Instituto Federal de Educação Ciência e Tecnologia (IFPE). Email: aline_miguelarcanjo@ @otmail.com;

${ }^{2}$ Autora. Discente do Curso de Bacharelado em Enfermagem do Instituto Federal de Educação Ciência e Tecnologia (IFPE). Email: Jullyanna_maria@hotmail.com;

${ }^{3}$ Orientadora. Docente do Curso de Bacharelado em Enfermagem do Instituto Federal de Educação Ciência e Tecnologia (IFPE). Doutora em Ciências da Saúde pelo Instituto Universitário Italiano de Rosário Argentina (IUNIR). Email: ana.alexandre@pesqueira.ifpe.edu.br;

${ }^{4}$ Co-orientadora. Docente do Curso de Bacharelado em Enfermagem do Instituto Federal de Educação Ciência e Tecnologia (IFPE). Email: claudia.leite@pesqueira.ifpe.edu.br;

${ }^{5}$ Co-orientador. Docente do Curso de Bacharelado em Enfermagem do Instituto Federal de Educação Ciência e Tecnologia (IFPE). Email: valdeilson-indio@hotmail.com.
} 


\section{Introdução}

A liderança consiste na influência que um líder exerce sob um grupo em função da originalidade de suas ideias e por buscar objetivos comuns com esse grupo. Trata-se de uma competência gerencial extremamente necessária e requisitada nos dias atuais, pois está presente em todos os tipos de organização humana e envolve diversos aspectos, como responsabilidade, compromisso, empatia, habilidade para tomada de decisões, comunicação e gerenciamento de forma efetiva e eficaz (CHIAVENATO, 2014).

A capacidade de liderar consiste em uma das principais competências a serem desenvolvidas por enfermeiros, pois o trabalho hospitalar, com suas constantes alterações tecnológicas e exigências da clientela, requer novas habilidades desses profissionais de saúde, o que ocasiona, como consequência imediata, transformações no seu processo de trabalho (BALSANELLI; CUNHA, 2016).

O mercado de trabalho tem exigido cada vez mais do enfermeiro a prática da liderança. As instituições de saúde procuram profissionais que estejam aptos a exercê-la para atingirem resultados eficazes. Assim, compreender a relação da liderança com a enfermagem é de fundamental importância para estabelecer planos de ação que proporcionem o desenvolvimento desta competência (AMESTOY et al., 2014).

No ambiente hospitalar, as atividades executadas transcorrem em meio à agitação e o estresse, exigindo atenção e cuidado rigorosos de todos os profissionais. Sendo assim, faz-se essencialmente importante a figura do líder como motivador e intermediador das relações nesse ambiente, de modo a diminuir a sobrecarga da equipe e impactar positivamente na recuperação do paciente (MELO, 2013).

No entanto, para que o enfermeiro exerça o seu papel de líder, a instituição de saúde deve possuir um modelo de gestão que favoreça o seu exercício. As Teorias da Liderança mais contemporâneas são apontadas como mais adequadas às realidades em que se tem um modelo de gestão mais descentralizado e emancipador, que valoriza e intensifica as relações interpessoais (SIMÕES; FAVARO, 2013).

No cenário atual da unidade hospitalar, verificam-se mudanças no modelo assistencial que busca distanciar-se do paradigma médico hegemônico e de relações de poder verticalizadas, abrindo espaço para novas formas de fazer saúde e para o fortalecimento e credibilidade nas 
ações do enfermeiro. Nesse contexto, emerge-se a necessidade de desenvolvimento da liderança do profissional de enfermagem (AMESTOY et al., 2014).

O enfermeiro, enquanto gerente, precisa estar preparado para assumir o papel de líder, condição básica para obter transformações no trabalho, atingir metas da organização e conciliar o trabalho em equipe. A complexidade e demanda de trabalho impostas ao enfermeiro exigem dinamicidade no gerenciamento de recursos, para que a assistência ocorra com qualidade, bem como a interdisciplinaridade e o contato com a família do paciente, na busca de um bom funcionamento do serviço (CARRION, 2016).

Nesse sentido, na unidade hospitalar, o enfermeiro necessita liderar seu grupo de trabalho para alcançar os melhores resultados, o que torna fundamental o uso da liderança como competência (BALSANELLI; CUNHA, 2015).

É necessário avançar no conhecimento sobre liderança e subsidiar a gestão em enfermagem, a fim de contribuir com o desenvolvimento dessa competência a partir dos resultados encontrados. Assim, pesquisas dessa natureza tem sua relevância ao tentar demonstrar os principais aspectos relacionados à liderança do enfermeiro na unidade hospitalar.

Assim, este estudo teve como objetivo caracterizar a produção cientifica, a respeitos de publicações referentes à liderança na enfermagem em unidades hospitalares.

\section{Método}

Estudo do tipo revisão integrativa. Esse método permite reunir, avaliar e sintetizar os resultados de pesquisas sobre tema específico, sendo capaz de gerar novas abordagens e perspectivas sobre o assunto revisado. Ademais, oferece o rigor requerido na pesquisa científica e a legitimidade das evidências estabelecidas (LAKATOS; MARCONI, 2010).

A operacionalização da revisão integrativa seguiu as seguintes etapas: a) seleção da questão temática; b) identificação dos descritores; c) seleção dos artigos com base em critérios de inclusão e exclusão, com posterior categorização por conteúdo temático; d) coleta e sistematização dos dados; e) análise e interpretação dos resultados (MENDES; SILVEIRA; GALVÃO, 2008).

Inicialmente estabeleceu a seguinte questão norteadora: Qual a produção científica acerca da liderança em Enfermagem? 
Delimitada a questão, os descritores ou palavras-chave são utilizados para a execução da busca dos estudos. Para esta revisão integrativa, os descritores em Ciências da Saúde (DeCS) selecionados foram: Liderança, Enfermeiro e Unidade Hospitalar.

Na seleção dos artigos científicos, foram adotados critérios de inclusão e exclusão para seleção dos trabalhos. Os critérios de inclusão foram artigos originais publicados nos últimos 9 anos, em periódicos nacionais e internacionais, indexados nos bancos de dados selecionados, que abordassem aspectos da liderança dos enfermeiros em uma unidade hospitalar. Os critérios de exclusão foram os artigos incompletos ou extraídos de teses e dissertações.

Os dados foram coletados na rede mundial de computadores (internet) em artigos disponíveis nas seguintes bases de dados: Literatura Latino-Americana em Ciências de Saúde (LILACS), na base de dados Bibliográficos Especializada na Área de Enfermagem do Brasil (BDENF), na Medical Literatur e Analysis and Retrieval System Online (MEDLINE/PUBMED) e na Scientific Electronic Library Online (SciELO).

A coleta de dados ocorreu entre os meses de abril e maio de 2018, contemplando o preenchimento de um instrumento composto das seguintes variáveis: país de origem do estudo; título; descritores; ano de publicação; ano de realização; periódico de publicação; qualificação no sistema Qualis da Coordenação de Aperfeiçoamento de Ensino Superior (CAPES); tipo de estudo; nível de evidência e sujeito do estudo.

A avaliação de cada artigo se deu com base no sistema de classificação hierárquica das evidências. Esse sistema para a avaliação de pesquisas ou outras fontes de informação proporciona subsídios para auxiliar o enfermeiro na avaliação crítica de resultados oriundos de pesquisas e na tomada de decisão sobre a incorporação das evidências à prática clínica (GALVÃO, 2016).

A qualidade das evidências é classificada em seis níveis, a saber: nível I, meta-análise de múltiplos estudos controlados e randomizados; nível II, estudos individuais com delineamento experimental; nível III, estudos com delineamento quase-experimental como estudo sem randomização com grupo único pré e pós-teste, séries temporais ou caso-controle; nível IV, estudos descritivos com delineamento não-experimental como pesquisa descritiva correlacional e qualitativa ou estudos de caso; nível $\mathrm{V}$, relatos de casos ou dados obtidos de forma sistemática, de qualidade verificável ou dados de avaliação de programas; nível VI, opiniões de especialistas respeitáveis baseadas na competência clínica ou opinião de comitês 
de especialistas, incluindo interpretações de informações não baseadas em pesquisas (GALVÃO, 2016).

Os resultados foram apresentados de forma descritiva, com auxílio de tabelas e gráficos. A princípio através da base de dados foram encontrados 109 artigos, por critérios de exclusão 82 das amostras encontradas foram descartadas, obtendo como amostra final 27 artigos. A partir dos dados coletados procedeu-se a análise dos resultados. Dessa forma, são apresentados os principais referenciais teóricos que analisam o tema de liderança dos enfermeiros que atuam em uma unidade hospitalar.

\section{Resultados}

Foram encontrados 27 estudos de acordo com os descritores selecionados em língua portuguesa. Para categorização, eles foram organizados em um código de identificação de A 01 até $\mathrm{A}-27$. Os 27 estudos, ou 100\% das publicações, foram realizados no Brasil entre os anos de 2009 e 2016, conforme apresentado na tabela 1 e tabela 2 (em anexo).

É possível observar que não há um padrão no número de estudos realizados e publicados ao longo dos anos. Verifica-se que o ano de 2012 teve o maior número de estudos realizados. Contudo, somente a partir de 2013 eles foram publicados. O ano de 2016 foi o mais expressivo em termos de estudos publicados.

Tabela 1. Caracterização das publicações encontradas conforme o ano de realização e publicação.

\begin{tabular}{ccccc}
\hline Ano & $\begin{array}{c}\text { Número de } \\
\text { estudos } \\
\text { realizados }\end{array}$ & $\%$ & $\begin{array}{c}\text { Número de } \\
\text { estudos } \\
\text { publicados }\end{array}$ & $\%$ \\
\hline 2009 & 4 & 14,81 & 0 & 0 \\
2010 & 1 & 3,70 & 0 & 0 \\
2011 & 3 & 11,11 & 0 & 0 \\
2012 & 7 & 25,92 & 0 & 0 \\
2013 & 2 & 7,40 & 7 & 25,92 \\
2014 & 5 & 18,51 & 3 & 11,11 \\
2015 & 3 & 11,11 & 3 & 11,11 \\
2016 & 2 & 7,40 & 12 & 44,44 \\
2017 & 0 & 0 & 1 & 3,70 \\
2018 & 0 & 0 & 1 & 3,70 \\
& 27 & $100 \%$ & 27 & $100 \%$ \\
\hline
\end{tabular}

Fonte: Pesquisa dos autores. 
Quanto à categorização dos estudos no sistema Qualis Capes, observa-se no gráfico 01 que 59,25\% ( $\mathrm{n}=16)$ dos artigos se classificam na categoria A. Contudo, apenas um deles encontra-se na categoria A1, a mais elevada. As categorias B1 e B2 concentram juntas 37,03\% $(n=10)$. A Categoria B4, que tem avaliação inferior em relação às demais, aparece com 3,70\% $(\mathrm{n}=1)$. A predominância dos periódicos nas categorias mais bem avaliadas pelo Qualis Capes indica a qualidade dos dados pesquisados.

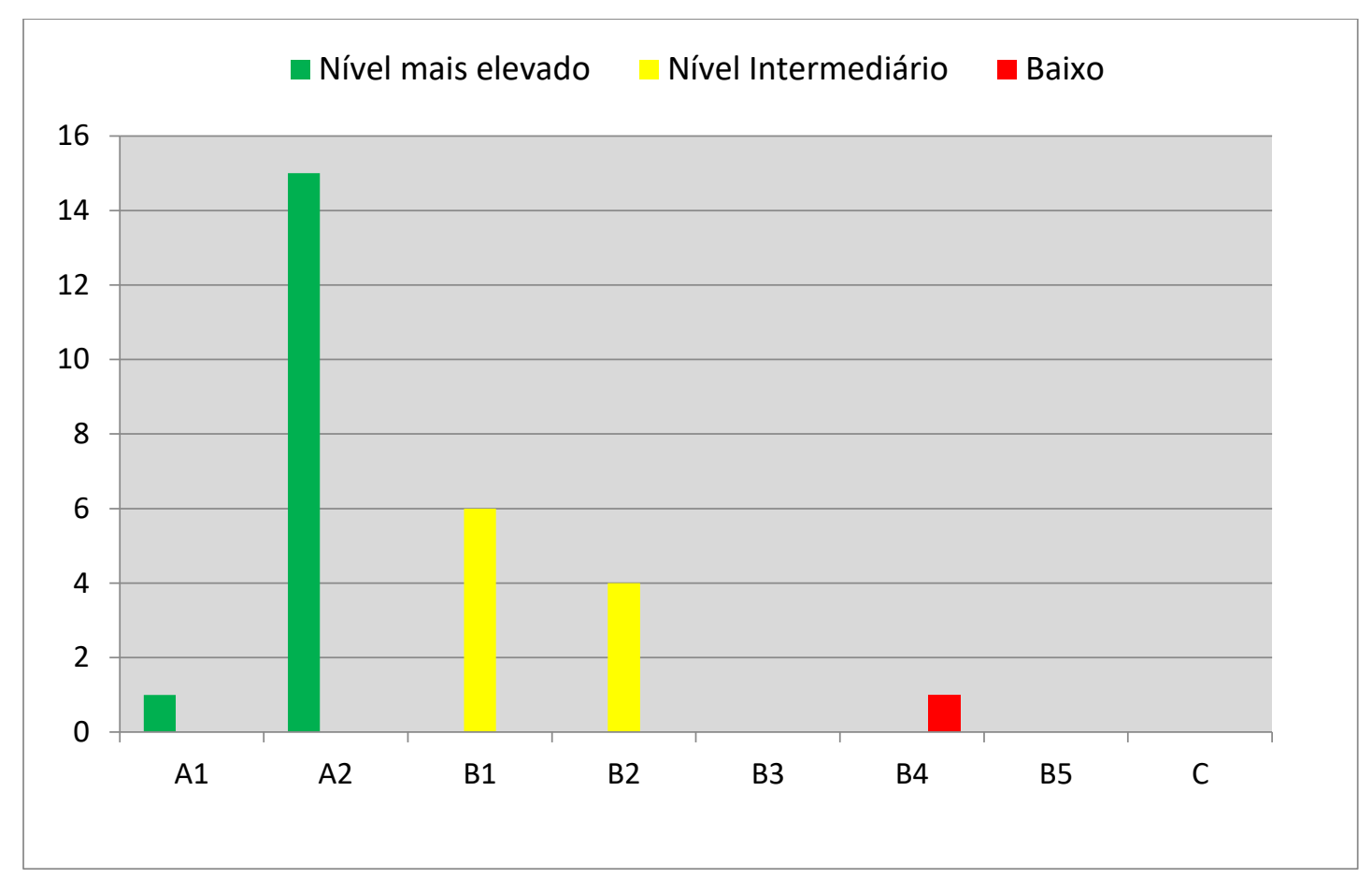

Gráfico 01: Classificação dos estudos no Qualis CAPES.

Quanto aos sujeitos do estudo, verificou-se que 70,37\% (n=19), possuem o público-alvo exclusivamente composto por enfermeiros. Outros sujeitos-alvo das pesquisas eram técnicos de enfermagem, estudantes de graduação, auxiliares, e até pacientes, médicos e dentistas, conforme se observa no gráfico 2. Quando se avalia aspectos da liderança na enfermagem, os estudos apontam que o enfermeiro aparece como principal objeto de estudo quanto a esta temática. Todavia, outros atores precisam ser observados, pois a liderança dos enfermeiros numa unidade hospitalar acaba por causar reflexos também entre os demais membros da equipe de enfermagem, bem como os profissionais multidisciplinares. 


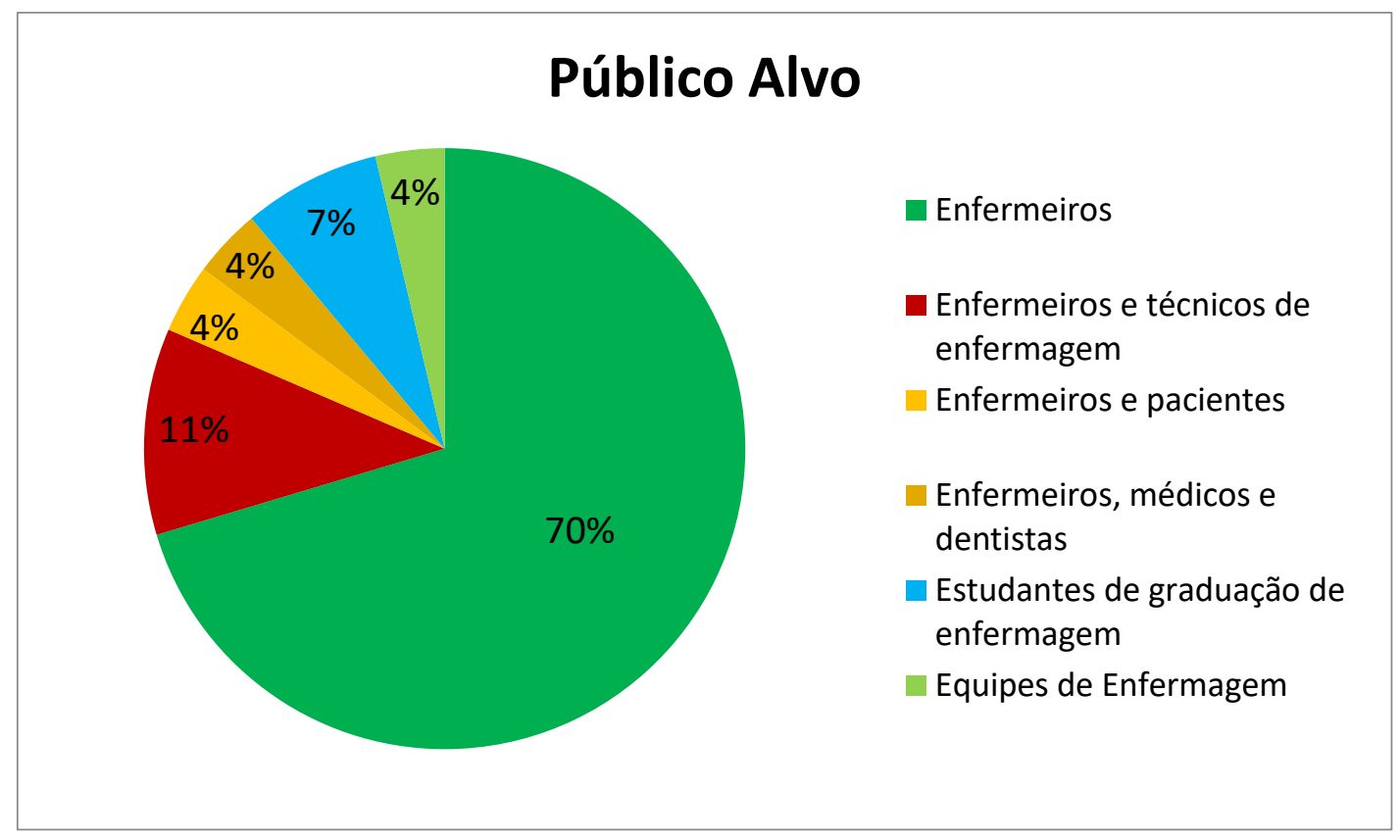

Gráfico 02: Sujeitos do estudo.

Em relação ao nível de evidência, verifica-se o nível IV na totalidade dos estudos encontrados conforme apresentado no gráfico 3. Portanto, dentre os selecionados predominaram estudos descritivos com delineamento não-experimental como pesquisa descritiva correlaciona e qualitativa ou estudos de caso.

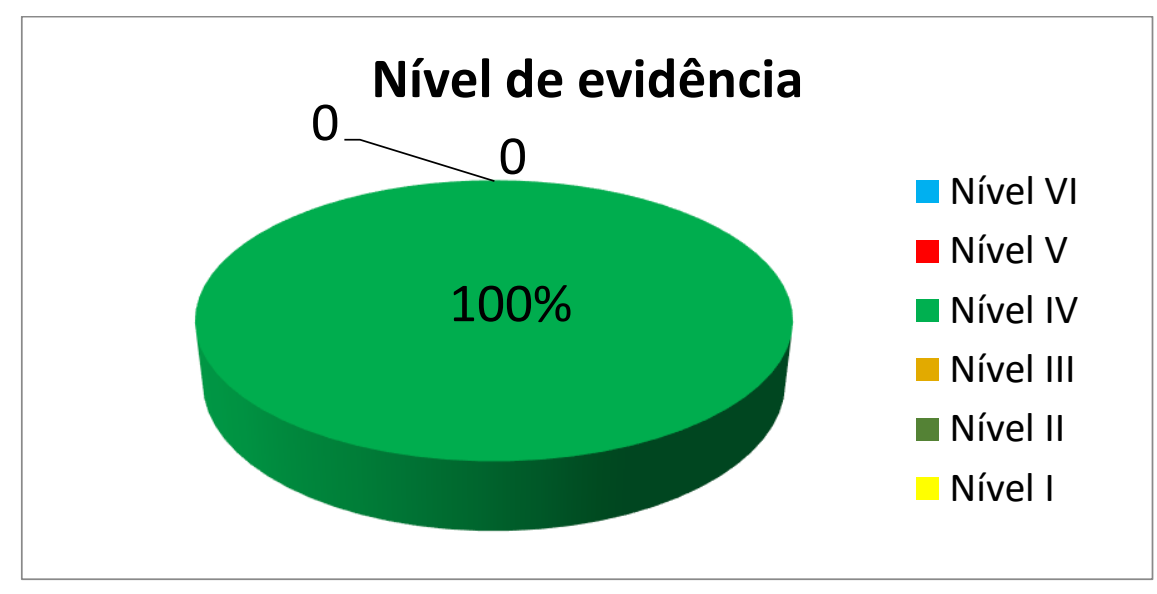

Gráfico 03: Nível de evidência.

Quanto ao tipo de estudo, observou-se a frequência de três deles. Conforme o gráfico 04. A correlação liderança e enfermagem têm sido pesquisadas na literatura, sobretudo através 
de estudos descritivos $(62,96 \%)$ e transversais $(29,62 \%)$. Constata-se também a predominância de estudos qualitativos em detrimento de estudos quantitativos e exploratórios.

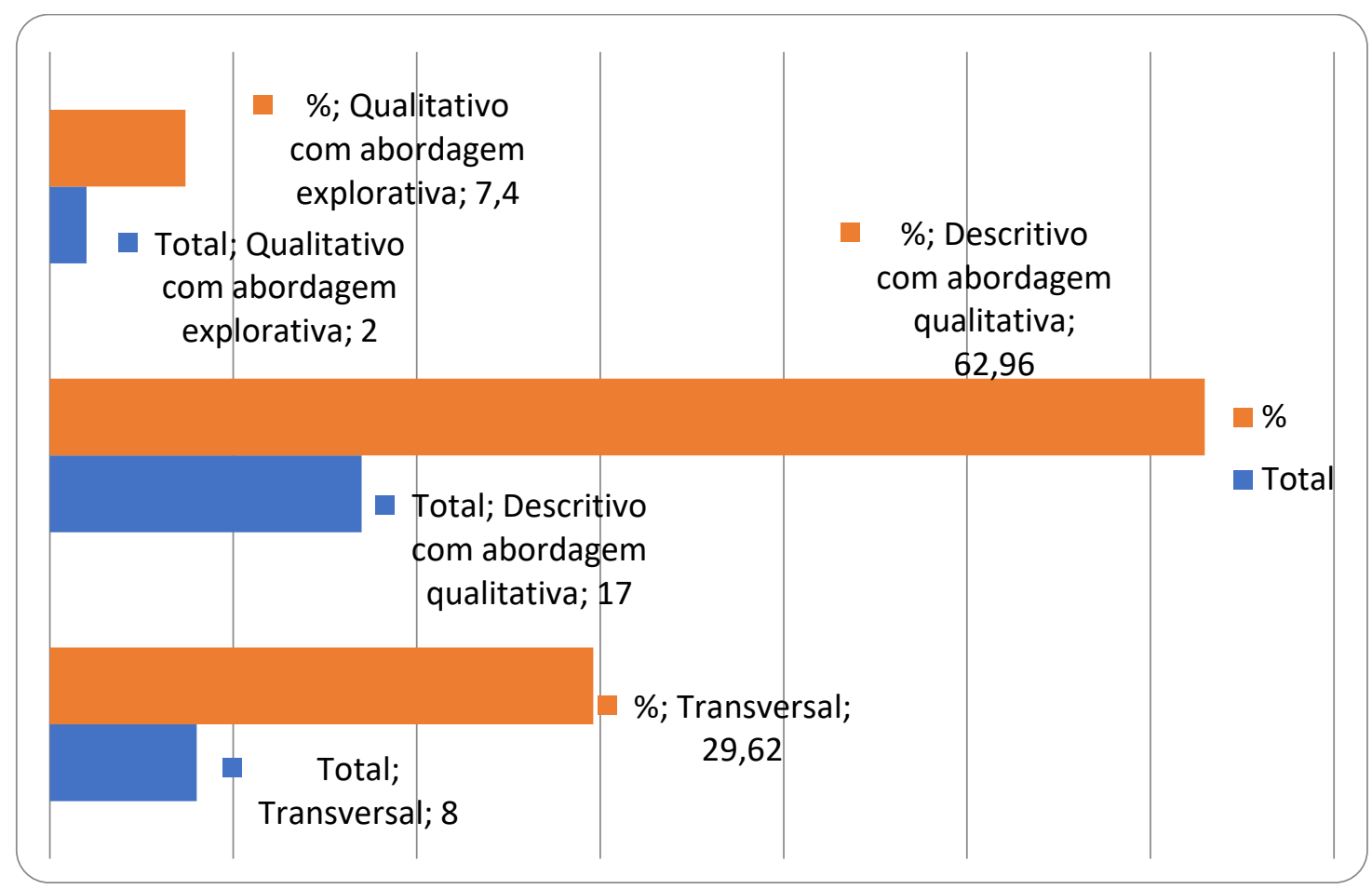

Gráfico 04: Tipos de Estudo.

\section{Discussão}

A literatura investigada demonstra que a relação entre liderança e enfermeiros tem ocupado espaço em publicações nacionais. Corroborando afirmação de Carrion (2016) de que a liderança tem sido objeto de estudo de diversos teóricos e uma preocupação constante das organizações.

Observa-se a prevalência de estudos recentes, que expressam diferentes pontos de vista e explicações a respeito da liderança do enfermeiro no contexto hospitalar.

Os estudos selecionados foram em sua maioria categorizados no nível Qualis Capes mais elevado. Nestes estudos a liderança é compreendida como uma influência interpessoal exercida numa dada situação e dirigida através do processo de comunicação humana para a consecução de um ou mais objetivos específicos. 
Os estudos analisados caracterizam a liderança do enfermeiro conforme os seguintes elementos: a influência, a situação, o processo de comunicação e os objetivos a alcançar.

A liderança conduz as pessoas para que façam o que é necessário por livre e espontânea vontade. Sendo, então, o desejo de controlar eventos, a sabedoria de indicar uma rota a ser seguida e o poder de fazer com que uma ação seja realizada, usando cooperativamente as capacidades e habilidades de outras pessoas é necessária em todos os tipos de organização humana (CHIAVENATO, 2014).

Portanto, a liderança do enfermeiro ocorre a partir de sua capacidade de influenciar as pessoas e saber aglutiná-las em torno de um objetivo comum. Assim, sempre que o enfermeiro coordenar/dirigir uma situação específica, influenciar o outro a tomar certas atitudes, estará liderando.

Os estudos selecionados evidenciam que liderar é a habilidade de exercer influência, de modo intencional, através de um processo de relações interpessoais adequadas para a consecução de um ou mais objetivos comuns a todos os participantes. Neste sentido, o líder pode ser entendido como o sujeito capaz de influenciar as pessoas, a agir de modo que queiram fazer o que precisa ser feito (AMESTOY et al, 2014).

A partir da análise é possível classificar a liderança como fenômeno tipicamente social, que acontece no contexto de grupos. Desse modo, os estudos encontrados abordam a liderança do enfermeiro não somente a partir da ótica do enfermeiro, como também das equipes de enfermagem, estudantes, médicos e pacientes.

Os estudos foram em sua totalidade classificados no Nível IV de Evidência, não sendo encontradas publicações em outras categorias de evidência. É possível observar que apesar de ser publicado num Qualis bom, o nível de evidencia é baixo.

Os estudos demonstram também que a liderança é algo fundamental para o trabalho do enfermeiro e se manifesta na sua habilidade de influenciar sua equipe, de forma que juntos possam alcançar objetivos compartilhados, tendo como finalidade central o atendimento das necessidades de saúde dos pacientes e suas famílias.

No espaço assistencial, principalmente no hospitalar, é o enfermeiro que articula diferentes serviços, realizando a coordenação do cuidado, desempenhando um papel silencioso no cotidiano de trabalho, visando garantir os insumos necessários ao cuidado. Assumir o cuidado significa ter responsabilidade de articular os diferentes profissionais, em um trabalho 
em equipe, interdisciplinar, horizontal, de colaboração, visando o sujeito do cuidado em sua integralidade bio-psico-social (GELBECK, 2016).

Em $70 \%$ dos estudos da amostra, observa-se o enfermeiro como protagonista no processo de liderança. Assim, afirma-se a importância dessa classe para a organização dos serviços hospitalares. A literatura indica que o trabalho do enfermeiro abrange a organização do serviço de modo que cada membro da equipe de enfermagem colabore com eficiência e competência na assistência à saúde de pessoas que necessitam desse atendimento.

O enfermeiro que atua com liderança deve reconhecer o valor de cada membro de sua equipe, visando estabelecer a liderança responsável, onde a confiança e a busca contínua de conhecimento prevaleçam. Entretanto, torna-se relevante que esse profissional aprimore constantemente seus conhecimentos para que possa responder às necessidades da equipe e instituição (MELO,2013).

O profissional enfermeiro, para promover um gerenciamento dos recursos humanos da área da enfermagem necessita conhecer a capacidade e a disposição de seus colaboradores e aliá-las ao nível de complexidade exigidos pela clientela. Todavia, sendo um ambiente interativo em que as decisões precisam ser rápidas e assertivas, muitas vezes, observa-se uma postura autoritária ao invés da participativa (BALSANELLI, CUNHA, 2016).

Neste sentido, cabe ao líder estimular a criatividade dos liderados, criar vínculos e promover discussões coletivas, permitir que participem dos processos decisórios e desenvolver o trabalho em equipe, de forma a alcançar o sucesso nos atendimentos prestados. A liderança pode e deve ser aprendida pelo enfermeiro. A busca de meios que viabilizem o desenvolvimento da habilidade de liderar do enfermeiro é fundamental (SILVA, 2014).

O enfermeiro-líder representa o elo de apoio da equipe no que se refere à coordenação do serviço. Assim, esse profissional tem o compromisso de estimular o desenvolvimento do potencial coletivo, o que irá interferir diretamente na qualidade da assistência (CHEREGATTI; AMORIN, 2010).

Os estudos indicam que a natureza do trabalho do enfermeiro e suas responsabilidades para o gerenciamento da assistência de enfermagem devem estar fundamentadas na capacidade para tomar decisões, com o uso apropriado da força de trabalho, de recursos materiais e de procedimentos e práticas. O domínio de competências gerenciais contribui para atuação deste profissional, por meio da aplicação de seus conhecimentos administrativos, técnicos e relacionais (CARRION, 2016). 
Todavia, este profissional enfrenta dificuldades que interferem no exercício da liderança no contexto da unidade hospitalar. O ambiente complexo e tenso, característico de um hospital, pode contribuir na geração de conflitos. Nesse contexto, a comunicação é um instrumento fundamental para facilitar a construção de relações mais harmônicas. A comunicação é necessária, uma vez que contribui na superação das diferenças e dos conflitos, no ambiente (AMESTOY et. al, 2014).

A literatura indica que o enfermeiro precisa estar capacitado a exercer atividades de liderança, para as quais é necessária a autoconfiança respaldada no conhecimento científico para que este possa conduzir o atendimento do paciente com segurança. Para tal, o treinamento deste profissional é imprescindível para o alcance do resultado esperado.

Os estudos destacam que gerenciar equipe, tomar decisões, solucionar conflitos, dentre outros, o enfermeiro desenvolve-se como líder.

\section{Conclusões}

Os resultados aqui obtidos através da revisão integrativa demonstram relevância acadêmica e social, no intuito de efetivar a importância de enfermeiros como líderes de equipe para se obter sucesso no atendimento de pacientes no âmbito da unidade hospitalar.

Observa-se a necessidade da competência liderança para identificar e intervir nas alterações fisiológicas dos pacientes, amenizar a ansiedade desses e de seus familiares, utilizar os recursos tecnológicos que compõem esse ambiente e facilitar a interdisciplinaridade.

Bem como, a capacidade para zelar pela manutenção e organização do ambiente, junto com os demais membros de sua equipe e decidir sobre o uso apropriado de recursos humanos, físicos, materiais e de informação no cuidado ao paciente, visando o trabalho em equipe, a eficácia e custo-efetividade.

No contexto atual, o exercício da liderança representa uma realidade que permeia as ações do enfermeiro, em virtude da frequente ocupação de cargos de chefia nos serviços de saúde. O impacto da liderança do enfermeiro na unidade hospitalar é significativo.

Assim, ressalta-se a importância da realização de pesquisas que tragam conceitos inovadores e que possam servir de referência para a prática profissional. 


\section{Referências}

AMESTOY, Simone Coelho et al. Gerenciamento de conflitos: desafios vivenciados pelos enfermeiros-líder no ambiente hospitalar. Rev. Gaucha .Enfermagem. 2014; 35(2):79-85. Disponível <http://seer.ufrgs.br/index.php/RevistaGauchadeEnfermagem/article/view/40155> Acesso em: 06 de março de 2018.

BALSANELLI, Alexandre Pazzeto; CUNHA, Isabel Cristina KowalOlm. Liderança ideal e real dos enfermeiros de unidade de terapia intensiva em hospitais privados

e públicos. Rev. Cogitare Enfermagem. 2016 Jan/mar; 21(1): 01-07. Disponível em <https://www.researchgate.net/publication/300368254>Acesso em: 06 de março de 2018.

. Liderança do enfermeiro em unidade de terapia intensiva e sua relação com ambiente de trabalho. Rev. Latino-Am. Enfermagem. Jan. 2015; 23(1):106-13. Disponível em http://www.scielo.br/pdf/rlae/v23n1/pt_0104-1169-rlae-23-01-00106.pdf> Acesso em: 06 de março de 2018.

CARRION, Maria da Conceição Dias. A Arte de Liderar na Enfermagem. 1 ed. São Paulo: Baraúna, 2016.

CHEREGATTI, Aline Laurenti; AMORIM, Carolina Padrão. Enfermagem em Unidade de Terapia Intensiva. 12 ed. São Paulo: Martinari; 2010.

CHIAVENATO, Idalberto. Administração nos novos tempos. 3 ed. Rio de Janeiro: Manole, 2014.

GALVÃO, Cristina Maria. Níveis de Evidência. Rev. Acta Paul Enfermagem. 2016; 19(2):5. Disponível em <http://www.scielo.br/pdf/ape/v19n2/a01v19n2.pdf> Acesso em: 21 de abril de 2018.

GELBCKE, Francine Lima et al. Liderança em ambientes de cuidados críticos: reflexões e desafios à enfermagem brasileira. Rev. Bras. Enfermagem. Mar, 2016. 62(1):136-9. Disponível em < http://www.scielo.br/ pdf/reben/v62n1/21.pdf > Acesso em: 07 de outubro de 2017.

LAKATOS, E. M.; MARCONI M. A. Fundamentos de Metodologia Científica. 7 ed. São Paulo: Atlas, 2010.

MELO, Marcio Vieira. Estresse dos profissionais de saúde nas unidades hospitalares de atendimento em urgência e emergência. Cadernos de Graduação - Ciências Biológicas e da Saúde Facipe, Recife. v. 1. n. 2 . p. 35-42 | nov. 2013. Disponível em<https://periodicos.set.edu.br/index.php/facipesaude/article/download/1200/580> Acesso em: 20 de março de 2018. 
MENDES, Karina Dal Sasso; SILVEIRA, Renata Cristina Campos Pereira; GALVÃO, Cristina Maria. Revisão integrativa: método de pesquisa para a incorporação de evidências na saúde e na enfermagem. Texto Contexto Enfermagem. Florianópolis, 2008; 17(4):758-64. Disponível em <http://www.scielo.br/pdf/tce/v17n4/18.pdf> Acesso em: 25 de abril de 2018.

SILVA, Danielle Soares et al. A liderança do enfermeiro no contexto dos serviços de urgência e emergência. Rev. Eletr. Enfermagem. [Internet]. Jan/mar, 2014; 16(1): 211-9. Disponível

em<https://www.researchgate.net/publication/273715251_A_lideranca_do_enfermeiro_no_co ntexto_dos_servicos_de_urgencia_e_emergencia> Acesso em: 07 de abril de 2018.

SIMÕES, Ana Lúcia; FAVARO, Neide. O desafio da liderança para o enfermeiro. Rev Latino-am Enfermagem 2013; 11(5): 567-73. Disponível em $<$ http://www.scielo.br/scielo.php?pid=S010411692003000500002\&script=sci_abstract\&tlng= pt> Acesso em: 20 de março de 2018

\section{Como citar este artigo (Formato ABNT):}

SOBRINHO, Aline Bezerra; BERNARDO, Juliana Maria S.; ALEXANDRE, Ana Carla S.; LEITESALGUEIRO, Cláudia Daniele B.; OLIVEIRA, Valdeilson Lima de. Liderança do Enfermeiro: Reflexões Sobre o Papel do Enfermeiro no Contexto Hospitalar. Id on Line Rev.Mult. Psic., 2018, vol.12, n.41, p.693-710. ISSN: 1981-1179.

Recebido: 03/07/2018

Aceito 12/07/2018 
Tabela 2 - Características dos estudos selecionados.

\begin{tabular}{|c|c|c|c|c|c|c|c|c|c|c|}
\hline $\begin{array}{l}\text { C } \\
\text { ó } \\
\text { d. }\end{array}$ & $\begin{array}{l}\text { País de } \\
\text { origem }\end{array}$ & Titulo & Descritores & $\begin{array}{l}\text { Ano de } \\
\text { Publicação }\end{array}$ & $\begin{array}{l}\text { Ano de } \\
\text { realizaçã } \\
\text { o }\end{array}$ & Periódico & $\begin{array}{l}\text { Quali } \\
\text { s } \\
\text { Capes }\end{array}$ & $\begin{array}{l}\text { Tipo de } \\
\text { estudo }\end{array}$ & $\begin{array}{l}\text { Nível de } \\
\text { evidência }\end{array}$ & $\begin{array}{l}\text { Sujeito do } \\
\text { estudo }\end{array}$ \\
\hline $\begin{array}{l}\text { A } \\
- \\
0 \\
1\end{array}$ & Brasil & $\begin{array}{l}\text { O exercício da } \\
\text { liderança sob a } \\
\text { ótica de } \\
\text { enfermeiros de } \\
\text { pronto socorro }\end{array}$ & $\begin{array}{l}\text { Enfermagem } \\
\text { em } \\
\text { emergência; } \\
\text { Liderança; } \\
\text { Pesquisa em } \\
\text { administração } \\
\text { de } \\
\text { enfermagem. }\end{array}$ & 2014 & 2011 & $\begin{array}{l}\text { Revista } \\
\text { Cogitarem } \\
\text { Enfermage } \\
\mathrm{m}\end{array}$ & B1 & $\begin{array}{l}\text { Estudo } \\
\text { descritivo } \\
\text { com } \\
\text { abordagem } \\
\text { qualitativa }\end{array}$ & IV & $\begin{array}{l}\text { Enfermeir } \\
\text { os }\end{array}$ \\
\hline $\begin{array}{l}\text { A } \\
- \\
0 \\
2\end{array}$ & Brasil & $\begin{array}{l}\text { Liderança ideal } \\
\text { e real dos } \\
\text { enfermeiros de } \\
\text { unidade de } \\
\text { terapia intensiva } \\
\text { em hospitais } \\
\text { privados e } \\
\text { públicos }\end{array}$ & $\begin{array}{l}\text { Enfermagem; } \\
\text { Liderança; } \\
\text { Unidades de } \\
\text { Terapia } \\
\text { Intensiva. }\end{array}$ & 2016 & 2013 & $\begin{array}{l}\text { Revista } \\
\text { Cogitarem } \\
\text { Enfermage } \\
\mathrm{m}\end{array}$ & B1 & $\begin{array}{l}\text { Estudo } \\
\text { transversal }\end{array}$ & IV & $\begin{array}{l}\text { Enfermeir } \\
\text { os e Téc. } \\
\text { Enfermag } \\
\text { em. }\end{array}$ \\
\hline $\begin{array}{l}\text { A } \\
- \\
0 \\
3\end{array}$ & Brasil & $\begin{array}{l}\text { Estilos de } \\
\text { liderança } \\
\text { situacional } \\
\text { adotados pelos } \\
\text { enfermeiros na } \\
\text { área hospitalar }\end{array}$ & $\begin{array}{l}\text { Pesquisa em } \\
\text { Administração } \\
\text { de } \\
\text { Enfermagem; } \\
\text { Liderança; } \\
\text { Pratica } \\
\text { Profissional; } \\
\text { Serviços de } \\
\text { Saúde. }\end{array}$ & 2016 & 2016 & $\begin{array}{l}\text { Revista } \\
\text { Eletrônica } \\
\text { de } \\
\text { Enfermage } \\
\mathrm{m}\end{array}$ & B1 & $\begin{array}{l}\text { Estudo } \\
\text { descritivo } \\
\text { com } \\
\text { abordagem } \\
\text { qualitativa }\end{array}$ & IV & $\begin{array}{l}\text { Enfermeir } \\
\text { os }\end{array}$ \\
\hline $\begin{array}{l}\text { A } \\
- \\
0 \\
4\end{array}$ & Brasil & $\begin{array}{l}\text { Percepção de } \\
\text { enfermeiros- } \\
\text { líderes sobre o } \\
\text { gerenciamento } \\
\text { de conflitos no } \\
\text { ambiente } \\
\text { hospitalar }\end{array}$ & $\begin{array}{l}\text { Enfermagem; } \\
\text { Liderança; } \\
\text { Serviços } \\
\text { hospitalares. }\end{array}$ & 2016 & 2014 & $\begin{array}{l}\text { Revista de } \\
\text { Enfermage } \\
\text { m da UFSM }\end{array}$ & B2 & $\begin{array}{l}\text { Estudo } \\
\text { descritivo } \\
\text { com } \\
\text { abordagem } \\
\text { qualitativa }\end{array}$ & IV & $\begin{array}{l}\text { Enfermeir } \\
\text { os }\end{array}$ \\
\hline $\begin{array}{l}A \\
- \\
0 \\
5\end{array}$ & Brasil & $\begin{array}{l}\text { Compreendendo } \\
\text { o significado da } \\
\text { liderança para o } \\
\text { aluno de } \\
\text { graduação } \\
\text { Em } \\
\text { enfermagem: } \\
\text { uma abordagem } \\
\text { fenomenológica }\end{array}$ & $\begin{array}{l}\text { Liderança; } \\
\text { Educação em } \\
\text { Enfermagem; } \\
\text { Pesquisa } \\
\text { Qualitativa. }\end{array}$ & 2013 & 2012 & $\begin{array}{l}\text { Revista } \\
\text { Brasileira de } \\
\text { Enfermage } \\
\mathrm{m}\end{array}$ & $\mathrm{A} 2$ & $\begin{array}{l}\text { Estudo } \\
\text { descritivo } \\
\text { com } \\
\text { abordagem } \\
\text { qualitativa }\end{array}$ & IV & $\begin{array}{l}\text { Estudante } \\
\text { s de } \\
\text { graduação } \\
\text { de } \\
\text { enfermage } \\
\text { m }\end{array}$ \\
\hline
\end{tabular}




\begin{tabular}{|c|c|c|c|c|c|c|c|c|c|c|}
\hline $\begin{array}{l}\text { A } \\
- \\
0 \\
6\end{array}$ & Brasil & $\begin{array}{l}\text { Competências } \\
\text { profissionais } \\
\text { para } \\
\text { enfermeiros: a } \\
\text { visão de } \\
\text { discentes de } \\
\text { graduação em } \\
\text { enfermagem }\end{array}$ & $\begin{array}{l}\text { Competência } \\
\text { Profissional; } \\
\text { Enfermagem; } \\
\text { Bacharelado } \\
\text { em } \\
\text { Enfermagem; } \\
\text { Educação } \\
\text { Superior. }\end{array}$ & 2016 & 2015 & $\begin{array}{l}\text { Revista } \\
\text { Baiana de } \\
\text { Enfermage } \\
\text { m, Salvador }\end{array}$ & B2 & $\begin{array}{l}\text { Estudo } \\
\text { descritivo } \\
\text { com } \\
\text { abordagem } \\
\text { qualitativa }\end{array}$ & IV & $\begin{array}{l}\text { Estudante } \\
\text { s de } \\
\text { graduação } \\
\text { de } \\
\text { enfermage } \\
\text { m }\end{array}$ \\
\hline $\begin{array}{l}\text { A } \\
- \\
0 \\
7\end{array}$ & Brasil & $\begin{array}{l}\text { Conceitos e } \\
\text { práticas de } \\
\text { ensino e } \\
\text { exercício da } \\
\text { liderança em } \\
\text { enfermagem }\end{array}$ & $\begin{array}{l}\text { História da } \\
\text { Enfermagem; } \\
\text { Educação em } \\
\text { Enfermagem; } \\
\text { Ensino } \\
\text { Superior; } \\
\text { Liderança; } \\
\text { Pesquisa em } \\
\text { Administração } \\
\text { de } \\
\text { Enfermagem }\end{array}$ & 2018 & 2011 & $\begin{array}{l}\text { Revista } \\
\text { Brasileira de } \\
\text { Enfermage } \\
\mathrm{m}\end{array}$ & $\mathrm{A} 2$ & $\begin{array}{l}\text { Estudo } \\
\text { transversal }\end{array}$ & IV & $\begin{array}{l}\text { Enfermeir } \\
\text { os }\end{array}$ \\
\hline $\begin{array}{l}\text { A } \\
- \\
0 \\
8\end{array}$ & Brasil & $\begin{array}{l}\text { Gerência do } \\
\text { cuidado e } \\
\text { governança de } \\
\text { enfermagemem } \\
\text { uma } \\
\text { maternidade: } \\
\text { teoria } \\
\text { fundamentada }\end{array}$ & $\begin{array}{l}\text { Gerência; } \\
\text { Cuidados de } \\
\text { Enfermagem; } \\
\text { Supervisão de } \\
\text { Enfermagem; } \\
\text { Enfermagem } \\
\text { Obstétrica; } \\
\text { Pesquisa em } \\
\text { Administração } \\
\text { de } \\
\text { Enfermagem. }\end{array}$ & 2017 & 2016 & $\begin{array}{l}\text { Revista } \\
\text { Brasileira de } \\
\text { Enfermage } \\
\mathrm{m}\end{array}$ & A2 & $\begin{array}{l}\text { Estudo } \\
\text { transversal }\end{array}$ & IV & $\begin{array}{l}\text { Enfermeir } \\
\text { os }\end{array}$ \\
\hline $\begin{array}{l}\text { A } \\
- \\
0 \\
9\end{array}$ & Brasil & $\begin{array}{l}\text { Liderança } \\
\text { autêntica e } \\
\text { perfil pessoal e } \\
\text { profissional de } \\
\text { enfermeiros }\end{array}$ & $\begin{array}{l}\text { Liderança; } \\
\text { Competência } \\
\text { profissionais; } \\
\text { Recursos } \\
\text { humanos de } \\
\text { enfermagem; } \\
\text { Questionários }\end{array}$ & 2016 & 2014 & $\begin{array}{l}\text { Acta } \\
\text { paulista de } \\
\text { enfermagem }\end{array}$ & A2 & $\begin{array}{l}\text { Estudo } \\
\text { transversal }\end{array}$ & IV & $\begin{array}{l}\text { Enfermeir } \\
\text { os }\end{array}$ \\
\hline $\begin{array}{l}\text { A } \\
- \\
1 \\
0\end{array}$ & Brasil & $\begin{array}{l}\text { Práticas de } \\
\text { liderança em } \\
\text { enfermagem } \\
\text { hospitalar: uma } \\
\text { self de } \\
\text { enfermeiros } \\
\text { gestores* }\end{array}$ & $\begin{array}{l}\text { Enfermagem; } \\
\text { Liderança; } \\
\text { Gestão; } \\
\text { Enfermagem; } \\
\text { Liderança; } \\
\text { Gestão; } \\
\text { Serviço de } \\
\text { Enfermagem } \\
\text { Hospitalar; } \\
\text { Enfermagem, } \\
\text { Supervisão; }\end{array}$ & 2016 & 2014 & $\begin{array}{l}\text { Revista da } \\
\text { escola de } \\
\text { enfermagem } \\
\text { da USP }\end{array}$ & A2 & $\begin{array}{l}\text { Estudo } \\
\text { transversal }\end{array}$ & IV & $\begin{array}{l}\text { Enfermeir } \\
\text { os }\end{array}$ \\
\hline
\end{tabular}




\begin{tabular}{|c|c|c|c|c|c|c|c|c|c|c|}
\hline & & & $\begin{array}{l}\text { Administração } \\
\text { Hospitalar } \\
\text { Serviço de } \\
\text { Enfermagem } \\
\text { Hospitalar; } \\
\text { Enfermagem, } \\
\text { Supervisão; } \\
\text { Administração } \\
\text { Hospitalar }\end{array}$ & & & & & & & \\
\hline $\begin{array}{l}\text { A } \\
- \\
1 \\
1\end{array}$ & Brasil & $\begin{array}{l}\text { Liderança do } \\
\text { enfermeiro em } \\
\text { unidade de } \\
\text { terapia intensiva } \\
\text { e sua relação } \\
\text { com ambiente } \\
\text { de trabalho }\end{array}$ & $\begin{array}{l}\text { Enfermagem; } \\
\text { Liderança; } \\
\text { Unidades de } \\
\text { Terapia } \\
\text { Intensiva; } \\
\text { Ambiente de } \\
\text { Instituições de } \\
\text { Saúde. }\end{array}$ & 2015 & 2012 & $\begin{array}{l}\text { Rev. Latino- } \\
\text { Am. } \\
\text { Enfermage } \\
\text { m }\end{array}$ & A1 & $\begin{array}{l}\text { Estudo } \\
\text { transversal }\end{array}$ & IV & $\begin{array}{l}\text { Enfermeir } \\
\text { os e } \\
\text { técnicos } \\
\text { em } \\
\text { enfermage } \\
\text { m }\end{array}$ \\
\hline $\begin{array}{l}\text { A } \\
- \\
1 \\
2\end{array}$ & Brasil & $\begin{array}{l}\text { O enfermeiro no } \\
\text { pós-operatório } \\
\text { de cirurgia } \\
\text { cardíaca: } \\
\text { competências } \\
\text { profissionais e } \\
\text { estratégias da } \\
\text { organização }\end{array}$ & $\begin{array}{l}\text { Enfermagem } \\
\text { Pré- } \\
\text { operatória; } \\
\text { Competência } \\
\text { profissional; } \\
\text { Cirurgia } \\
\text { torácica; Pós- } \\
\text { operatório. } \\
\text { Período; } \\
\text { Estratégias }\end{array}$ & 2016 & 2014 & $\begin{array}{l}\text { Revista da } \\
\text { escola de } \\
\text { enfermagem } \\
\text { da USP }\end{array}$ & A2 & $\begin{array}{l}\text { Estudo } \\
\text { descritivo } \\
\text { com } \\
\text { abordagem } \\
\text { qualitativa }\end{array}$ & IV & $\begin{array}{l}\text { Enfermeir } \\
\text { os }\end{array}$ \\
\hline $\begin{array}{l}\text { A } \\
- \\
1 \\
3\end{array}$ & Brasil & $\begin{array}{l}\text { Percepção dos } \\
\text { enfermeiros } \\
\text { sobre o processo } \\
\text { de ensino } \\
\text { aprendizagem } \\
\text { da liderança } \\
\end{array}$ & $\begin{array}{l}\text { Enfermagem. } \\
\text { Liderança. } \\
\text { Educação em } \\
\text { enfermagem. }\end{array}$ & 2013 & 2010 & $\begin{array}{l}\text { Revista } \\
\text { texto } \\
\text { Contexto } \\
\text { Enfermage } \\
\text { m. }\end{array}$ & & $\begin{array}{l}\text { Abordagem } \\
\text { qualitativa } \\
\text { do tipo } \\
\text { descritivo, }\end{array}$ & IV & $\begin{array}{l}\text { Enfermeir } \\
\text { os }\end{array}$ \\
\hline $\begin{array}{l}\text { A } \\
- \\
1 \\
4\end{array}$ & Brasil & $\begin{array}{l}\text { Desafios para a } \\
\text { gerência do } \\
\text { cuidado em } \\
\text { emergência na } \\
\text { perspectiva de } \\
\text { enfermeiros }\end{array}$ & $\begin{array}{l}\text { Pesquisa em } \\
\text { administração } \\
\text { de } \\
\text { Enfermagem; } \\
\text { Serviço } \\
\text { hospitalar. } \\
\text { De } \\
\text { enfermagem; } \\
\text { Cuidados de. } \\
\text { Enfermagem; } \\
\text { Gerência; } \\
\text { Enfermagem. } \\
\text { Em } \\
\text { emergência }\end{array}$ & 2013 & 2009 & $\begin{array}{l}\text { Acta } \\
\text { Paulista de } \\
\text { Enfermage } \\
\mathrm{m}\end{array}$ & $\mathrm{A} 2$ & $\begin{array}{l}\text { Abordagem } \\
\text { qualitativa } \\
\text { do tipo } \\
\text { descritiva, }\end{array}$ & IV & $\begin{array}{l}\text { Enfermeir } \\
\text { os }\end{array}$ \\
\hline $\begin{array}{l}\text { A } \\
- \\
1 \\
5\end{array}$ & Brasil & $\begin{array}{l}\text { Expectativas da } \\
\text { equipe de } \\
\text { enfermagem } \\
\text { em relação à } \\
\text { liderança }\end{array}$ & $\begin{array}{l}\text { Liderança; } \\
\text { Equipe de } \\
\text { enfermagem; } \\
\text { Serviço } \\
\text { hospitalar de } \\
\text { enfermagem; } \\
\text { Pesquisa em } \\
\text { administração } \\
\text { de } \\
\text { Enfermagem; } \\
\text { Recursos } \\
\text { humanos de } \\
\text { Enfermagem }\end{array}$ & 2013 & 2009 & $\begin{array}{l}\text { Acta } \\
\text { Paulista de } \\
\text { Enfermage } \\
\mathrm{m}\end{array}$ & A2 & $\begin{array}{l}\text { Abordagem } \\
\text { qualitativa } \\
\text { do tipo } \\
\text { descritiva }\end{array}$ & IV & $\begin{array}{l}\text { Enfermeir } \\
\text { os, } \\
\text { técnicos } \\
\text { e } \\
\text { auxiliares } \\
\text { de } \\
\text { enfermage } \\
\text { m }\end{array}$ \\
\hline
\end{tabular}




\begin{tabular}{|c|c|c|c|c|c|c|c|c|c|c|}
\hline $\begin{array}{l}\text { A } \\
- \\
1 \\
6\end{array}$ & Brasil & $\begin{array}{l}\text { Liderança do } \\
\text { enfermeiro: } \\
\text { elemento } \\
\text { interveniente na } \\
\text { rede de } \\
\text { relações do } \\
\text { agente } \\
\text { comunitário de } \\
\text { saúde }\end{array}$ & $\begin{array}{l}\text { Enfermagem; } \\
\text { Liderança; } \\
\text { Saúde da } \\
\text { Família; } \\
\text { Atenção } \\
\text { Primaria a } \\
\text { Saúde; } \\
\text { Relações } \\
\text { Interpessoais. }\end{array}$ & 2013 & 2009 & $\begin{array}{l}\text { Revista } \\
\text { Brasileira de } \\
\text { Enfermage } \\
\mathrm{m}\end{array}$ & A2 & $\begin{array}{l}\text { Abordagem } \\
\text { qualitativa } \\
\text { do tipo } \\
\text { descritivo }\end{array}$ & IV & $\begin{array}{l}\text { ACS, } \\
\text { enfermeir } \\
\text { os, } \\
\text { medicos e } \\
\text { dentistas. }\end{array}$ \\
\hline $\begin{array}{l}\text { A } \\
- \\
1 \\
7\end{array}$ & Brasil & $\begin{array}{l}\text { Exercício da } \\
\text { liderança do (a) } \\
\text { enfermeiro (a) } \\
\text { em unidades } \\
\text { oncológicas }\end{array}$ & $\begin{array}{l}\text { Enfermagem; } \\
\text { Liderança; } \\
\text { Oncologia; } \\
\text { Serviços de } \\
\text { Saúde. }\end{array}$ & 2016 & 2015 & $\begin{array}{l}\text { Revista } \\
\text { Baiana de } \\
\text { Enfermage } \\
\text { mSalvador. }\end{array}$ & B2 & $\begin{array}{l}\text { Abordagem } \\
\text { qualitativa } \\
\text { do tipo } \\
\text { descritivo }\end{array}$ & IV & $\begin{array}{l}\text { Enfermeir } \\
\text { os }\end{array}$ \\
\hline $\begin{array}{l}\text { A } \\
- \\
1 \\
8\end{array}$ & Brasil & $\begin{array}{l}\text { Exercício da } \\
\text { liderança do } \\
\text { enfermeiro em } \\
\text { unidade de } \\
\text { terapia intensiva }\end{array}$ & $\begin{array}{l}\text { Enfermagem; } \\
\text { Liderança; } \\
\text { Unidade de } \\
\text { terapia } \\
\text { intensiva; } \\
\text { Serviços de } \\
\text { saúde. }\end{array}$ & 2014 & 2014 & $\begin{array}{l}\text { JOURNAL } \\
\text { OF } \\
\text { NURSING } \\
\text { AND } \\
\text { HEALTH }\end{array}$ & B4 & $\begin{array}{l}\text { Abordagem } \\
\text { qualitativa } \\
\text { do tipo } \\
\text { descritivo }\end{array}$ & IV & $\begin{array}{l}\text { Enfermeir } \\
\text { os }\end{array}$ \\
\hline $\begin{array}{l}\text { A } \\
- \\
1 \\
9\end{array}$ & Brasil & $\begin{array}{l}\text { Facilidades e } \\
\text { dificuldades do } \\
\text { trabalho em } \\
\text { terapia } \\
\text { intensiva: um } \\
\text { olhar da equipe } \\
\text { de enfermagem }\end{array}$ & $\begin{array}{l}\text { Unidades de } \\
\text { terapia } \\
\text { intensiva } \\
\text { (UTI); equipe } \\
\text { de } \\
\text { enfermagem; } \\
\text { trabalhos. }\end{array}$ & 2016 & 2012 & $\begin{array}{l}\text { RESEARC } \\
\mathrm{H}\end{array}$ & A2 & $\begin{array}{l}\text { Abordagem } \\
\text { qualitativa } \\
\text { do tipo } \\
\text { descritiva }\end{array}$ & IV & $\begin{array}{l}\text { Enfermeir } \\
\text { os }\end{array}$ \\
\hline $\begin{array}{l}\text { A } \\
- \\
2 \\
0\end{array}$ & Brasil & $\begin{array}{l}\text { Enfermagem e } \\
\text { liderança: } \\
\text { percepções de } \\
\text { enfermeiros } \\
\text { gestores de um } \\
\text { hospital do sul } \\
\text { do Brasil }\end{array}$ & $\begin{array}{l}\text { Liderança, } \\
\text { Gestão, } \\
\text { Enfermagem. }\end{array}$ & 2015 & 2011 & $\begin{array}{l}\text { RESEARC } \\
\mathrm{H}\end{array}$ & A2 & $\begin{array}{l}\text { Abordagem } \\
\text { qualitativa } \\
\text { do tipo } \\
\text { descritiva }\end{array}$ & IV & $\begin{array}{l}\text { Enfermeir } \\
\text { os }\end{array}$ \\
\hline $\begin{array}{l}\text { A } \\
- \\
2 \\
1\end{array}$ & Brasil & $\begin{array}{l}\text { Liderança do } \\
\text { enfermeiro } \\
\text { responsável } \\
\text { técnico: um } \\
\text { fazer necessário } \\
\text { para o exercício } \\
\text { profissional }\end{array}$ & $\begin{array}{l}\text { Pesquisa em } \\
\text { enfermagem } \\
\text { equipe de } \\
\text { enfermagem, } \\
\text { liderança. }\end{array}$ & 2014 & 2012 & $\begin{array}{l}\text { RESEARC } \\
\mathrm{H}\end{array}$ & $\mathrm{A} 2$ & $\begin{array}{l}\text { explorativad } \\
\text { iscutiva }\end{array}$ & IV & $\begin{array}{l}\text { Enfermeir } \\
\text { os }\end{array}$ \\
\hline $\begin{array}{l}\text { A } \\
- \\
2 \\
2\end{array}$ & Brasil & $\begin{array}{l}\text { Competências } \\
\text { gerenciais } \\
\text { requeridas de } \\
\text { enfermeiros em } \\
\text { um pronto- } \\
\text { socorro }\end{array}$ & $\begin{array}{l}\text {.Enfermagem, } \\
\text { Enfermagem } \\
\text { em } \\
\text { emergência, } \\
\text { Pesquisa em } \\
\text { administração } \\
\text { de } \\
\text { enfermagem, } \\
\text { Gerenciament } \\
\text { o de prática } \\
\text { profissional. }\end{array}$ & 2013 & 2009 & $\begin{array}{l}\text { RESEARC } \\
\mathrm{H}\end{array}$ & A2 & $\begin{array}{l}\text { Qualitativa } \\
\text { do tipo de } \\
\text { abordagem } \\
\text { descritivo }\end{array}$ & IV & $\begin{array}{l}\text { Enfermeir } \\
\text { os }\end{array}$ \\
\hline $\begin{array}{l}\text { A } \\
- \\
2 \\
3\end{array}$ & Brasil & $\begin{array}{l}\text { Análise da pro } \\
\text { atividade da } \\
\text { enfermagem em } \\
\text { um hospital } \\
\text { universitário } \\
\text { público }\end{array}$ & $\begin{array}{l}\text { Desempenho } \\
\text { laboral; } \\
\text { Equipe de. } \\
\text { Enfermagem; } \\
\text { Liderança; } \\
\text { Ambiente. } \\
\text { De trabalho; } \\
\text { Serviço } \\
\text { hospitalar de. } \\
\text { Enfermagem }\end{array}$ & 2016 & 2015 & $\begin{array}{l}\text { Acta } \\
\text { Paulista de } \\
\text { Enfermage } \\
\mathrm{m}\end{array}$ & A2 & $\begin{array}{l}\text { Estudo } \\
\text { transversal }\end{array}$ & IV & $\begin{array}{l}\text { Enfermeir } \\
\text { os }\end{array}$ \\
\hline
\end{tabular}




\begin{tabular}{|c|c|c|c|c|c|c|c|c|c|c|}
\hline $\begin{array}{l}\text { A } \\
- \\
2 \\
4\end{array}$ & Brasil & $\begin{array}{l}\text { Repercussões da } \\
\text { pro atividade no } \\
\text { gerenciamento } \\
\text { do cuidado: } \\
\text { percepções de } \\
\text { enfermeiros }\end{array}$ & $\begin{array}{l}\text { Papel do } \\
\text { profissional } \\
\text { de } \\
\text { enfermagem; } \\
\text { Gestão em } \\
\text { saúde; } \\
\text { Enfermagem. }\end{array}$ & 2016 & 2012 & $\begin{array}{l}\text { Escola Anna } \\
\text { Nery }\end{array}$ & B1 & $\begin{array}{l}\text { Qualitativa } \\
\text { do tipo de } \\
\text { abordagem } \\
\text { descritivo }\end{array}$ & IV & $\begin{array}{l}\text { Enfermeir } \\
\text { os }\end{array}$ \\
\hline $\begin{array}{l}\text { A } \\
- \\
2 \\
5\end{array}$ & Brasil & $\begin{array}{l}\text { Desvelando } \\
\text { competências } \\
\text { do enfermeiro } \\
\text { de terapia } \\
\text { intensiva }\end{array}$ & $\begin{array}{l}\text { Competência } \\
\text { profissional; } \\
\text { Unidades de } \\
\text { terapia } \\
\text { intensiva; } \\
\text { Enfermagem. }\end{array}$ & 2015 & 2012 & $\begin{array}{l}\text { Enfermage } \\
\mathrm{m} \text { em Foco }\end{array}$ & B2 & $\begin{array}{l}\text { Qualitativa } \\
\text { do tipo de } \\
\text { abordagem } \\
\text { explorativa }\end{array}$ & IV & $\begin{array}{l}\text { Enfermeir } \\
\text { os }\end{array}$ \\
\hline $\begin{array}{l}\text { A } \\
- \\
2 \\
6\end{array}$ & Brasil & $\begin{array}{l}\text { A liderança em } \\
\text { enfermagem e a } \\
\text { satisfação dos } \\
\text { pacientes em } \\
\text { contexto } \\
\text { hospitalar }\end{array}$ & $\begin{array}{l}\text { Serviços de } \\
\text { enfermagem. } \\
\text { Cuidados de } \\
\text { enfermagem. } \\
\text { Liderança. } \\
\text { Satisfação do } \\
\text { paciente }\end{array}$ & 2016 & 2013 & $\begin{array}{l}\text { Revista } \\
\text { Gaúcha de } \\
\text { Enfermage } \\
\mathrm{m}\end{array}$ & B1 & $\begin{array}{l}\text { Estudo } \\
\text { transversal }\end{array}$ & IV & $\begin{array}{l}\text { Enfermeir } \\
\text { os e } \\
\text { pacientes }\end{array}$ \\
\hline $\begin{array}{l}\text { A } \\
- \\
2 \\
7\end{array}$ & Brasil & $\begin{array}{l}\text { Compreensões } \\
\text { de liderança } \\
\text { pela equipe de } \\
\text { enfermagem }\end{array}$ & $\begin{array}{l}\text { Liderança; } \\
\text { Administração } \\
\text { hospitalar; } \\
\text { Equipe de } \\
\text { enfermagem. }\end{array}$ & 2013 & 2012 & $\begin{array}{l}\text { Revista } \\
\text { Cogitarem } \\
\text { Enfermage } \\
\mathrm{m}\end{array}$ & B1 & $\begin{array}{l}\text { Qualitativa } \\
\text { do tipo de } \\
\text { abordagem } \\
\text { descritivo }\end{array}$ & IV & $\begin{array}{l}\text { Equipe de } \\
\text { enfermage } \\
\mathrm{m}\end{array}$ \\
\hline
\end{tabular}

